\title{
O Parque Nacional do Araguaia: dilemas entre o desenvolvimento regional e a conservação da natureza
}

\section{The Araguaia National Park: dilemmas between regional development and nature conservation}

\author{
Marcia Helena Lopes* \\ José Luiz de Andrade Franco*
}

\begin{abstract}
Resumo
O presente artigo trata das motivações e inciativas em torno da criação do Parque Nacional do Araguaia (PNA), especialmente dos dilemas entre o desenvolvimento regional e a conservação da natureza, com ênfase no período entre 1940 e 1960. Para tanto, foram utilizados vários tipos de fontes documentais, primárias e secundárias: livros, artigos publicados na mídia do estado de Goiás e do Rio de Janeiro, diários oficiais do estado de Goiás e do Congresso Nacional, relatório do Ministério da Agricultura e documentos da Fundação Brasil Central referentes à Operação Bananal, depoimentos e literatura de época. A pesquisa mostrou que houve muita ambiguidade e diversidade de perspectivas envolvidas na criação do PNA. A forma como ele começou a ser implementado acabou por desconsiderar os objetivos mais voltados para a conservação da natureza. Prevaleceu a visão desenvolvimentista, característica do período JK.
\end{abstract}

Palavras-chave: Parque Nacional do Araguaia; conservação da natureza; história ambiental.

\begin{abstract}
This article deals with the motivations and initiatives surrounding the creation of the Araguaia National Park (PNA), especially the dilemmas between regional development and nature conservation, with an emphasis on the period between 1940 and 1960. For this purpose, several documental sources were used, primary and secondary: books, articles published in newspapers of the state of Goiás and Rio de Janeiro, official press of the state of Goiás and the
\end{abstract}

\footnotetext{
*Doutora em Desenvolvimento Sustentável pela Universidade de Brasília.E-mail: malena.lopes@gmail.com ** Doutor em História pela Universidade de Brasília. Professor Associado do Departamento de História, do Programa de Pós-Graduação em História e do Programa de Pós-Graduação em Desenvolvimento Sustentável do Centro de Desenvolvimento Sustentável da Universidade de Brasília. E-mail: jldafranco@gmail.com
} 
National Congress, report from the Ministry of Agriculture and documents from the Fundação Brasil Central referring to Operation Bananal, testimonies and period literature. The research showed that there was a lot of ambiguity and diversity of perspectives involved in the creation of the PNA. The way it started to be implemented ended up disregarding the goals more focused on nature conservation. The developmentalist view, characteristic of the JK period, prevailed.

Keywords: Araguaia National Park; conservation of nature; environmental history.

\section{Introdução}

O parque nacional do Araguaia (PNA) é uma das áreas de proteção integral que compõem o Sistema Nacional de Unidades de Conservação da Natureza. Ele foi criado em 1959, sobre a totalidade do território da ilha do Bananal, localizada no médio curso do rio Araguaia, durante o governo do presidente Juscelino Kubitschek de Oliveira. ${ }^{1}$ O PNA foi o primeiro parque nacional constituído em área de ocorrência do bioma Cerrado com faixas de transição do bioma Amazônia.

A origem deste parque pode ser considerada emblemática, já que a primeira sugestão para que o Brasil adotasse o modelo norte-americano de conservação via parques nacionais fazia menção à sua criação. 0 ensaio inaugural sobre essa ideia, "Excursão ao Salto do Guayra", remonta ao período do Segundo Império e foi escrito pelo engenheiro André Pinto Rebouças, ${ }^{2}$ que influenciado pela inovação do país do Norte, defendeu a criação no Brasil de duas unidades desse tipo: uma na grande ilha fluvial do Bananal, na província de Goiás, e a outra no conjunto das grandes quedas d'água do Guayra, conhecido como Sete Quedas, no Paraná. Essas duas localidades, na visão de Rebouças, detinham qualidades ambientais excepcionais, e exemplificavam o grande potencial natural das terras nacionais. No entanto, o excepcional patrimônio natural da ilha do Bananal foi legalmente protegido apenas 83 anos mais tarde.

\footnotetext{
${ }^{1}$ Utilizarei a abreviatura JK para me referir ao presidente Juscelino Kubitschek de Oliveira, iniciais pelas quais ficou mundialmente conhecido.

${ }^{2}$ REBOUÇAS, André Pinto. Excursão ao Salto do Guayra ou Sete Quedas pelo Capitão Nestor Borba - Notas e considerações pelo Engenheiro André Rebouças. 1876. Revista Trimestral do Instituto Historico e Geographico Brasileiro, Tomo LXI. Rio de Janeiro: Imprensa Nacional, 1898, p.67-87.
} 
A literatura que aborda o processo de ocupação do vale do Araguaia, tem situado o PNA como resultado da expansão da fronteira econômica no Brasil Central. ${ }^{3}$ Sem necessariamente discordar desse aspecto, o presente trabalho procura olhar a origem deste parque a partir de um outro viés, que inclui uma sensibilidade para a questão da proteção da natureza. Assim, este artigo procura demonstrar que o discurso governamental de integração nacional dos anos 1950, entendido aqui como uma releitura da política estadonovista da Marcha para o Oeste, foi atravessado pela atuação na arena social de diferentes atores locais e nacionais sensíveis à questão da exploração irracional dos recursos naturais, o que possibilitou a construção de um cenário favorável ao reconhecimento da ilha do Bananal como um patrimônio natural a ser preservado.

Desde a primeira geração de intelectuais brasileiros protetores da natureza, os parques nacionais foram defendidos com base em valores científicos, estéticos e culturais, mas também econômicos relacionados à manutenção de um certo estoque de recursos considerados importantes ao bem-estar das gerações presentes e futuras. ${ }^{4}$ De fato, as preocupações relacionadas a um cuidado com o meio natural no Brasil remontam ao final do período colonial, envolvendo questões mais pragmáticas relativas ao uso previdente dos recursos naturais. ${ }^{5}$ Uma visão mais próxima da noção moderna de conservação começa a se manifestar a partir do final do século XIX, alcançando maior visibilidade e efetividade nos anos 1920-1940, quando a penetração de ideias conservacionistas na esfera do poder público e em alguns setores da sociedade possibilitou a aprovação de um corpo de leis voltadas à regulamentação do uso e proteção dos recursos naturais e a criação dos primeiros parques nacionais brasileiros. Essa nova realidade normativa foi acompanhada do aparelhamento do Estado para garantir uma razoável organização da gestão dos bens ambientais. ${ }^{6}$ Mesmo que os avanços desse período possam ser considerados modestos, eles representaram alguma atuação do Estado na gestão

\footnotetext{
${ }^{3}$ Ver: BORGES, Durval Rosa. Rio Araguaia Corpo e Alma. São Paulo: IBRASA/USP, 1987; GONÇALVES, Nélio Cerqueira. J. Kasos e Kasos sem J. Belo Horizonte: Editora Imprensa Oficial, 1984; OLIVEIRA, Juscelino Kubitschek. 50 anos em 5. Meu caminho para Brasilia. Rio de Janeiro: Edições Bloch, 1978; LIMA FILHO, Manuel Ferreira. 0 desencanto do Oeste: memória e identidade social no médio Araguaia. Goiânia: Editora UCG, 2001; TREVISAN, Ricardo et al. Operação Bananal: do domínio territorial ao balneário esquecido de Brasília. In: XIII Seminário de História da Cidade e do Urbanismo, Brasília, Anais do XIII SHCU, 2014.

${ }^{4}$ DEAN, Warren. A ferro e fogo: história e devastação da Mata Atlântica brasileira. São Paulo: Cia das Letras, 1996. ${ }^{5}$ PÁDUA, José Augusto. Um sopro de destruição. Pensamento político e crítica ambiental no Brasil escravista (1786 - 1888). Rio de Janeiro: Jorge Zahar, 2004.

${ }^{6}$ FRANCO, José Luiz Andrade; DRUMMOND, José Augusto. Proteção à Natureza e Identidade Nacional no Brasil, anos 1920-1940. Rio de Janeiro: Fiocruz, 2009.
} 
dos recursos naturais e, principalmente, estabeleceram as condições legais e institucionais oportunas às futuras propostas para a ampliação do número de parques nacionais no país.

Na década de 1950, o movimento pela conservação da natureza ganhou mais expressividade junto a determinados segmentos da sociedade civil, reunidos em torno da causa da proteção da natureza. Nesse sentido, pode-se dizer que, o governo JK herdou não somente condições legais e administrativas favoráveis ao desenvolvimento de políticas conservacionistas, mas também uma sociedade razoavelmente mais bem organizada para pressionar o poder público neste sentido. ${ }^{7}$ Assim, mesmo em face da hegemonia do discurso desenvolvimentista, o cenário político envolvendo a transferência da capital da República para o Planalto Central permitiu uma certa margem de articulação das ideias conservacionista junto ao poder federal, resultando em ações efetivas em prol do meio ambiente, como a criação de novos parques nacionais, dentre eles o PNA.

Este estudo segue a mesma linha de trabalhos recentes que abordam a relação sociedade e natureza no processo de ocupação histórica do Brasil Central. ${ }^{8} \mathrm{~A}$ originalidade aqui, está no enfoque dado à articulação política das ideias sobre a conservação da natureza no Estado de Goiás entre 1940 e 1960. A partir de uma perspectiva histórica, analisamos o movimento de expansão da fronteira Oeste, com ênfase no vale do Araguaia, em conexão com a emergência das ideias e ações para a proteção de seu patrimônio natural. Para tanto, utilizamos como fontes documentais artigos publicados na imprensa goiana e do Rio de Janeiro (1940-1960), Diários Oficiais do Estado de Goiás e

\footnotetext{
${ }^{7}$ Na década de 1950, quando o PNA foi criado, o movimento pela conservação da natureza ganhava mais expressividade com a organização da Fundação Brasileira para a Conservação da Natureza (FBCN), entidade de caráter civil que agregou pessoas de vários segmentos da sociedade em torno da causa da proteção da natureza.

${ }^{8}$ Ver: DUTRA E SILVA, Sandro. No Oeste, a terra e o céu. A expansão da fronteira agrícola no Brasil Central. Rio de Janeiro: Mauad X, 2017; OLIVEIRA, Lúcia Lippi. A natureza na interpretação do Oeste: sertão e fronteira no pensamento brasileiro. In: DUTRA e SILVA, Sandro; SÁ, Dominichi Miranda; SÁ, Magali Romero (orgs). Vastos Sertôes. História e Natureza na Ciência e na Literatura. Rio de Janeiro: Mauad X, 2015, p. 21-40; DUTRA e SILVA, Sandro. No caminho, um jatobá: enfrentamento e devastação da natureza na conquista do "último oeste". In: FRANCO, José Luiz Andrade; DUTRA e SILVA, Sandro; DRUMMOND, José Augusto; TAVARES, Giovana Galvão (orgs.), História Ambiental: fronteiras, recursos naturais e conservação da natureza. Rio de Janeiro: Garamond, 2012, p. 147-170; VITAL, André Vasques; TAVARES, Giovana Galvão; DUTRA e SILVA, Sandro; CAMPOS, Francisco Itami. As sedutoras águas do Oeste: as corredeiras e as quedas d'água na luta pela transferência da capital federal para o Brasil central (1892-1953). Revista de História IberoAmericana, V.10, N.2.05, p.122-144; WAKILD, Emily. Araguaia e Ilha do Bananal: um paradoxo da conservação e do uso compartilhado de recursos naturais no Brasil. In: DRUMMOND, José Augusto; FRANCO, José Luiz Andrade; DUTRA e SILVA, Sandro; BRAZ, Vivian (orgs). História Ambiental 3: natureza, sociedade, fronteira. Rio de Janeiro: Garamond, 2020, p. 201-225.
} 
do Congresso Nacional, relatórios do Ministério da Agricultura e documentos da Fundação Brasil Central, depoimentos e literatura de época.

\section{Ilha do Bananal: o paraíso turístico de caça e pesca no coração do Brasil}

Durante a primeira metade do século XX, a ilha do Bananal foi retratada pela imprensa goiana como um paraíso selvagem cuja riqueza e beleza natural constituíam verdadeiro patrimônio abandonado. Com a política de expansão da fronteira Oeste durante os anos 1940, o turismo sazonal na região do médio rio Araguaia começou a chamar a atenção como uma alternativa econômica. Se antes o rio era visitado praticamente pela população local, com o movimento de ocupação do Brasil Central a região passou a atrair também turistas de localidades distantes, notadamente São Paulo e Rio de Janeiro, para longas temporadas de caça, pesca e descanso. ${ }^{9}$

A visita do presidente Getúlio Vargas aos índios Karajá na ilha do Bananal, em agosto de 1940, teve um papel importante na visibilidade das belezas naturais do Araguaia, funcionando como uma propaganda poderosa do seu potencial turístico. Embora a viagem presidencial fizesse parte da estratégia midiática do governo para popularizar a campanha da Marcha para o Oeste, que visava estender o controle do poder central sobre o território nacional, acabou contribuindo para impulsionar o turismo na ilha. Em 27 de julho de 1941, o jornal Cidade de Goyaz destacava que: "Nas margens do Araguaia e circunjacências (sic), depois da vinda do Presidente Vargas a ilha do Bananal, intenso é o número de visitantes e turistas de toda parte que desejam conhecer os maravilhosos cenários araguaianos". ${ }^{10}$ No início da temporada do ano seguinte, o mesmo jornal divulgava a presença de Caravanas de turistas oriundas dos estados do Rio de Janeiro, São Paulo, Minas Gerais e Goiás em busca de emoções e das belezas do Araguaia. ${ }^{11}$

A emergência de um turismo interno que se estabelecia no sentido Leste-Oeste, pode ser entendido como um indicador do poder persuasivo das imagens, categorias e narrativas do Estado Novo. Segundo Garfield, ${ }^{12}$ a ida de Vargas à ilha do Bananal foi cercada de elementos simbólicos relacionados

\footnotetext{
${ }_{9}^{9}$ Jornal Voz do Povo 21/10/1933 p. 1; Jornal Cidade de Goiaz 07/08/1938, p.1; Jornal Cidade de Goyaz 17/05/1942 p.1, Jornal o Popular 03/10/46.

${ }^{10}$ Jornal Cidade de Goyaz, 27/07/1941, p. 1.

${ }^{11}$ Jornal Cidade de Goiaz, 17/05/1942, p.1.

${ }^{12}$ GARFIELD, Seth. As raízes de uma planta que hoje é o Brasil: os índios e o Estado-Nação na era Vargas. Revista Brasileira de História. São Paulo, V.20, N.39, p.15-42.
} 
a uma certa estética da aventura. As imagens fotográficas e audiovisuais, cuidadosamente produzidas e amplamente divulgadas pelo governo central, evocavam a figura do chefe da Nação à frente da conquista do território nacional, numa evidente alusão ao pioneiro desbravador, portador do estandarte da prosperidade, dos valores morais, éticos e civilizatórios. ${ }^{13}$ Dutra e Silva, ${ }^{14}$ destaca a importância da representação de um novo tipo bandeirante como elemento discursivo das políticas de colonização do Brasil Central nesse período. De forma geral, as imagens produzidas também tinham a intenção de valorizar o interior como locus de uma verdadeira brasilidade, situando-o em oposição ao litoral, que, embora mais desenvolvido, era desprovido de originalidade. ${ }^{15}$ Um aspecto importante levantado pelo autor refere-se ao fato da expansão da fronteira Oeste ter significado, de certa maneira, uma política bélica contra a natureza, vista como um obstáculo à expansão territorial e ao progresso econômico. ${ }^{16}$ Esta perspectiva vai ser notada na ilha do Bananal a partir do desenvolvimento de um tipo de turismo altamente predatório, estimulado pelos projetos de colonização no vale do Araguaia.

A política de colonização do interior transformou significativamente a paisagem do vale do Araguaia, com efeitos diretos sobre o Bananal. 0 projeto governamental de interiorização do desenvolvimento criou vias de comunicação, abriu pistas de pouso e fixou núcleos urbanos importantes como Aragarças, Nova Xavantina e Goiânia. Estas cidades, juntamente com as colônias agrícolas, tornaram-se em polos irradiadores de crescimento econômico e densidade demográfica. As ações do Estado deram maior visibilidade à região como um todo, o que fez com que a ilha do Bananal fosse inserida na rota das companhias aéreas comerciais como destino turístico. ${ }^{17}$

Tudo isso contribuiu para que no início dos anos 1950, as praias do Araguaia passassem a ser disputadas por um número cada vez maior de turistas, fossem eles locais, de outras regiões do país ou estrangeiros. Na capital

\footnotetext{
${ }^{13}$ O Departamento de Imprensa e Propaganda (DIP), órgão responsável pela difusão das diretrizes culturais e ideológicas estadonovistas, se encarregou de dar à expedição a feição de uma aventura épica a regiões tidas como impenetráveis, tendo o chefe da nação como personagem central.

${ }^{14}$ DUTRA E SILVA, Sandro. No Oeste ... op. cit..

${ }^{15}$ Sobre a oposição sertão/litoral no imaginário brasileiro ver: MAIA, João Marcelo Ehlert. A terra como invenção. O espaço no pensamento social brasileiro. Rio de Janeiro: Jorge Zahar, 2007. MAIA, João Marcelo Ehlert. As ideias que fazem o Estado andar: imaginação espacial, pensamento brasileiro e território no Brasil Central. DADOS - Revista de Ciências Sociais, Rio de Janeiro, V. 53, N.3, 2010, p. 621-655.

${ }^{16}$ DUTRA e SILVA, Sandro. No caminho... op. cit.

${ }^{17}$ Jornal Cidade de Goyaz 17/05/1942 p. 1; Jornal Cidade de Goyaz 26/08/1945 p.3; Jornal Cidade de Goyaz 27/10/1946 p. 3 e 10; Jornal Cidade de Goiás 07/02/1954 p.1-2; Jornal Cidade de Goiás, 07/02/1954 p.1-2; Jornal Cidade de Goiás, 07/02/1954 p.1-2.
} 
paulista, a agência de turismo Cinter organizava excursões de caça e pesca no interior da ilha do Bananal. As viagens eram comercializadas pela própria Cinter e por agências parceiras em sete cidades brasileiras - Rio de Janeiro (Avipam), Porto Alegre (Turismo Internacional Mônaco), Belo Horizonte (Pantour), Santos (Sr. Mair Pereira Leite), Curitiba (Aeromar), Joinville (Sr. Eurico Heinemann), Londrina (Proptur) - e em três capitais de países da América do Sul - Bueno Aires e Asunción (em ambas operando pela Ameropair) e Montevideo (pela própria Cinter). As excursões eram programadas para acontecer quinzenalmente, durante os quatro meses de estiagem. Essas agências costumavam publicar anúncios nos jornais e em revistas especializadas, como por exemplo a Revista Fauna, publicação mensal destinada à divulgação da caça e pesca desportiva no Brasil.

Mediada pelo imaginário ideológico do Estado Novo, a expansão do turismo no Araguaia foi orientada pelo desejo dos moradores das cidades por novas experiências de contato com a natureza selvagem. No entanto, essas novas experiências não eram do tipo meramente contemplativas do mundo selvagem, mas estavam associadas às emoções proporcionadas pelo domínio da natureza, representada principalmente pela caça da fauna nativa. A maior parte dos turistas que frequentava a ilha era do tipo caçador amador. Salvo os praticantes da caça e da pesca realmente desportiva, quem se embrenhava pelos campos e matas do Araguaia divertia-se alvejando, sem nenhum critério, gatos-do-mato, ariranhas, jacarés, onças-pintadas, veados, pacas, antas, capivaras, tartarugas, macacos, porcos-do-mato, além de todo o tipo de ave. A caça amadora aumentou significativamente a pressão sobre a fauna do Bananal. Mas, os turistas não foram os únicos a impactar o ambiente; caçadores profissionais tiveram uma cota importante na dizimação da fauna do Bananal. ${ }^{18}$

Embora a caça e a pesca sempre tenham sido os principais meios de subsistência dos moradores e viajantes dos sertões do Araguaia, a começar pelos muitos povos indígenas que historicamente ali se instalaram, como atividade comercial em maior escala, surgiram associadas ao processo de

\footnotetext{
${ }^{18}$ Ver: SILVA, Hermano Ribeiro. Nos Sertões do Araguaia. São Paulo: J. Fagundes, 1936; CAIADO, Leolídio di Ramos. Expedição Sertaneja Araguaia-Xingu. Goiânia: Bolsa de Publicações Hugo C, 1945; CAIADO, Leolídio di Ramos. Dramas do Oeste. História de uma excursão nas regiões da Ilha do Bananal. Goiânia: UNIGRAF, 1950; BERNARDES, Carmo. Jângala. Complexo Araguaia. Goiânia: Editora Autor, 1994.
} 
colonização e integração econômica da região. ${ }^{19}$ Segundo Vital \& Tejerina, ${ }^{20}$ entre os anos 1920 e 1930, Goiás chegou a incentivar o desenvolvimento da indústria extrativa animal no Araguaia, baseada na pesca do pirarucu e no comércio de peles. No entanto, todo o esforço de divulgação do potencial econômico da região foi frustrado pela falta de apoio do governo central à navegação fluvial. Foi somente a partir da política de colonização do Oeste que a atuação dos caçadores profissionais no Araguaia se tornou mais incisiva, estimulada pela demanda de peles e plumas nos mercados dos centros urbanos. Nesse contexto, os índios, colonos e sertanejos, que originalmente praticavam uma caça de subsistência, aderiram ao comércio e passaram a caçar também como meio de gerar renda. Era comum que comerciantes encomendassem lotes de peles e/ou de plumas diretamente com os moradores locais e com os índios. Muitas vezes, eles eram incorporados à economia regional como trabalhadores avulsos, operando como guias e auxiliares de caça e pesca nas expedições sertanejas e turísticas. ${ }^{21}$

Com o tempo, a ilha do Bananal se tornou o "quartel-general" dos caçadores e pescadores profissionais e amadores. A destruição contínua da fauna, somada à ineficiência do poder público em implementar uma política capaz de organizar e melhorar a fiscalização da atividade, causou a indignação de extratos da sociedade goiana, emocionalmente apegada e tradicionalmente orgulhosa do "seu" Araguaia. Intelectuais e políticos locais reagiram com críticas, mas também com iniciativas para a conservação da natureza na ilha do Bananal.

Em Goiás, o escritor Leolídio Di Ramos Caiado e o engenheiro e político Jerônimo Coimbra Bueno, ambos de tradicionais famílias goianas, estiveram na vanguarda da defesa do meio ambiente no estado. Enquanto Leolídio usou a literatura para denunciar os impactos ambientais e sociais da expansão da fronteira, envolvendo a situação lamentável da fauna silvestre, vítima de

\footnotetext{
${ }^{19}$ TORAL, André Amaral. 1992. Cosmologia e Sociedade Karajá. Tese (Doutorado em Antropologia). Universidade Federal do Rio de Janeiro, Museu Nacional, Rio de Janeiro, 1992; TORAL, André Amaral. 1999. Relatório de Identificação e Delimitação da Terra Indígena Inãwébohona. Brasília, FUNAI; LIMA FILHO, O desencanto... op. cit.; RODRIGUES, Patrícia Mendonça. 2013. Relatório Circunstanciado de Reestudo de Limites da Terra Indígena Tapirapé / Karajá. Brasília, FUNAI; FERRAZ, Luciana. 2012. Relatório Ambiental da Terra Indígena Javaé/Avá- Canoeiro. Brasília, FUNAI;

${ }^{20}$ VITAL, André Vasques; TEJERINA-GARRO, Francisco Leonardo. O incentivo à pesca comercial de Arapaima gigas (pirarucu) do rio Araguaia (Brasil Central) na revista “A Informação Goyana” (1917-1935). In: Boletim do Museu Paraense Emílio Goeldi. Ciências Humanas, V. 13, N. 1, jan./abr. 2018, p. 159-174.

${ }^{21}$ SILVA, Nos sertões... op. cit.; CAIADO, Leolídio di Ramos. Expedição... op. cit.; CAIADO, Leolídio di Ramos. Dramas... op. cit; VILLAS-BÔAS, Orlando; VILLAS-BÔAS, Cláudio. A Marcha para o Oeste. A epopeia da expedição Roncador-Xingu. 5ae ed., Rio de Janeiro, Editora Globo, 1994; RODRIGUES, Relatório... op. cit. 2013.
} 
verdadeiras chacinas, o desmatamento e queimadas, a grilagem de terras, o conflito entre o sertanejo pobre e o fazendeiro recém chegado, ${ }^{22}$ Coimbra Bueno seguiu o caminho político, sendo o grande articulador da criação dos três parques nacionais goianos: Araguaia, ${ }^{23}$ Emas e Veadeiros.

\section{A atuação de Jerônimo Coimbra Bueno em prol da conservação da natureza e do Parque Nacional do Araguaia}

Jerônimo Coimbra Bueno (1910 -1996) era natural de Rio Verde, cidade do sudoeste do estado de Goiás, e o primogênito dos seis filhos do casal Orozimbo Sousa Bueno e Umbelina Coimbra Bueno. Sua família paterna descendia dos Bueno, bandeirantes paulistas do século XVIII, aos quais se atribui as primeiras incursões no território goiano e a descoberta das minas de ouro no rio Vermelho. Bartolomeu Bueno Filho era seu tetravô. A família materna, ramo Coimbra, veio de Pernambuco, durante o ciclo do ouro em Goiás. Com o declínio da mineração, os Coimbra acabaram se radicando no Norte do estado como pecuaristas. Já os Bueno retornaram para São Paulo, indo se estabelecer depois no Espírito Santo. ${ }^{24}$

A transferência da família Coimbra para o sudoeste goiano se deu em razão de perseguições políticas por parte das oligarquias que comandavam o estado. Adquiriram fazendas na região entre Jataí e Rio Verde, se tornando grandes fazendeiros. Coimbra Bueno viveu até a adolescência nessa região de Cerrado, transferindo-se com sua família para Barretos, no interior de São Paulo, em 1925, e depois para o Rio de Janeiro, onde concluiu os estudos secundários. Em 1929, ingressou no curso de engenharia civil da Escola Politécnica do Rio de Janeiro, formando-se em engenharia, com especialização em urbanismo, em 1933. Seu irmão mais novo, Abelardo, seguiu o mesmo caminho, graduando-se pela mesma escola no ano seguinte.

Na Escola Politécnica, Coimbra Bueno recebeu uma instrução muito mais humanista que propriamente técnica. A tradição acadêmica da Politécnica, de influência francesa, combinava a formação científica de fundamentação ampla, com ênfase nas ciências básicas, o positivismo como código moral e o senso de missão cívica no exercício da vida profissional. A escola notabilizou-se

\footnotetext{
${ }^{22}$ Ver: CAIADO, Expedição... op. cit.; CAIADO, Dramas... op. cit. CAIADO, Leolídio di Ramos. Curichão da Saudade. Goiânia: UFG, 1963. CAIADO, Leolídio di Ramos. Arapoema. Goiânia: Oriente, 1975.

${ }^{23}$ Após 1989, com a separação do estado do Tocantins, o PNA ficou situado no novo estado.

${ }^{24}$ BUENO, Abelardo Coimbra. Depoimento de Abelardo Coimbra Bueno - Programa de História Oral, Arquivo Público do Distrito Federal, Brasília, 1990.
} 
por formar um tipo de profissional generalista, preparado para atuar em diversas frentes e assumir distintas funções públicas. ${ }^{25}$

No início de sua carreira como engenheiro, Coimbra Bueno foi convidado por Pedro Ludovico Teixeira, interventor de Goiás, a assumir a direção das obras da nova capital do estado, Goiânia. Após a transferência da administração estadual para a moderna cidade, em 1937, ele permaneceu como integrante do Conselho Técnico de Economia e Finanças de Goiás. A construção de Goiânia tem um sentido importante na trajetória de Coimbra Bueno. Primeiro porque marca o reencontro com sua origem sertaneja e o início da construção da sua imagem como homem político; segundo porque lhe proporciona dimensão ampliada do poder do urbanismo na modernização do país, fazendo com que, nos próximos anos, assumisse a transferência da capital federal para o Planalto Central como sua principal bandeira política.

Em Goiás, Coimbra Bueno se tornou uma figura pública conhecida por ter posições progressistas. Em 1947, assumiu o governo do estado, eleito pela coalizão entre a União Democrática Nacional (UDN) e uma ala dissidente do Partido Social Democrático (PSD). Apesar de ser um filho da terra, como político se apresentava como outsider. Em 1950, renunciou ao governo do estado para se dedicar à Comissão de Estudos e Localização da Nova Capital do Brasil. Como Governador, Coimbra Bueno se mostrou sensível à questão da exploração imprevidente dos recursos naturais no estado. Ele chegou a propor reformas significativas na legislação, voltadas à proteção da fauna e das reservas florestais, ao estabelecimento de uma polícia florestal estadual e à criação de áreas protegidas. Durante o seu governo foi instalado o Serviço de Caça e Pesca de Goiás. Na ocasião da inauguração do órgão, Coimbra Bueno argumentou que: "Já é tempo de dar cabo de uma anormalidade perigosa e destruidora que grassa pelo nosso Estado. Conhecidas de todos são as criminosas pescarias de bombas e outros métodos desaconselháveis (sic) cuja finalidade é a mera diversão de uns em detrimento do próprio sustento de uma população inteira" ${ }^{26}$

A região que mais chamava a atenção em razão da degradação ambiental era o médio rio Araguaia. Com o objetivo de promover um maior controle das atividades de caça e pesca predatórias, foi instalada na velha capital do estado, Cidade de Goiás, uma Inspetoria Regional do SCPG. Assim, a Inspetoria surgiu com a função primordial de fiscalizar e combater a destruição da fauna

\footnotetext{
${ }^{25}$ MAIA, João Marcelo Ehlert. A terra como invenção. O espaço no pensamento social brasileiro. Rio de Janeiro: Jorge Zahar, 2007.

${ }^{26}$ Jornal Cidade de Goiás 10/07/1949 p.1.
} 
e da flora no Araguaia. A presença desse órgão demonstrava que o governo tinha a intenção de atuar de maneira repressiva, mas também construtiva, propondo campanhas educativas sobre a pesca e a caça.

Além disso, Coimbra Bueno tinha em mente contemplar Goiás com vários parques nacionais, em diferentes regiões, começando por quatro localidades de grande beleza natural: o Canal de São Simão, a Serra de Caldas Novas, a Chapada dos Veadeiros e a Ilha do Bananal. Ele designou os estudos para subsidiar a elaboração dos projetos de lei referentes aos parques de Veadeiros e do Bananal, enviando-os ao poder legislativo estadual. ${ }^{27}$ Mas, como a oposição ao governador era maioria, os projetos foram rejeitados e nenhum parque foi criado na época. Embora ele não tenha obtido sucesso nesse período, o seu envolvimento com o movimento conservacionista, no final da década de 1950 e durante a década de 1960, foi decisivo para a ampliação das áreas protegidas no Brasil.

\section{A criação do Parque Nacional do Araguaia}

Anos mais tarde, a questão do Parque Nacional do Araguaia foi retomada na esfera política, desta vez pelo goiano Gerson de Castro Costa. Durante o Estado Novo, Costa ocupou vários cargos públicos, tendo sido chefe do Departamento Estadual de Cultura de Goiás e diretor do Departamento Estadual de Imprensa (DEIP), que tinha entre suas funções a promoção do turismo em Goiás. Foi também fundador e diretor do jornal Folha de Goiás. Como homem público, sempre destacou o potencial ambiental e turístico da ilha do Bananal, defendendo sua conservação como meio para o fortalecimento do turismo no Araguaia. Costa via o turismo como uma alternativa econômica importante para Goiás.

Costa era Deputado Estadual pela legenda do PSD na ocasião em que Coimbra Bueno enviou ao legislativo goiano sua proposta para os parques nacionais. Quase uma década mais tarde, já Deputado Federal por Goiás, ele retomou o debate em torno da conservação da ilha do Bananal, desta vez na esfera federal.

No início do mês de maio de 1959, Costa levou à apreciação do plenário da Câmara dos Deputados o Projeto de Lei (PL) no 256, visando a criação do "Parque Nacional da ilha do Bananal". Nas justificativas o documento alegava que há muitos anos a ilha era considerada uma localidade apropriada para receber um parque nacional. A peculiaridade insular da área, aclamada como a

${ }^{27}$ Diário Oficial do Estado de Goiás, 26/04/1950, p.8. 
maior ilha fluvial do mundo, somada à beleza e importância do seu patrimônio natural, tornou-a objeto de manifestações em defesa de sua conservação e destinação à visitação. A proposta era de que os limites da ilha serviriam de divisas ao parque, delimitado pela própria geografia do local. No total, uma área de 20 mil quilômetros quadrados abrigaria o "mais belo e extenso parque nacional do Brasil". ${ }^{28}$

O PL $n^{\circ} 256$ foi o primeiro documento formalmente encaminhado ao legislativo federal para a concretização do parque. Para subsidiar sua proposta, Costa encomendou ao geólogo e naturalista goiano Zoroastro Artiaga um estudo técnico a respeito das características ambientais da ilha, tanto em seus aspectos estéticos quanto econômicos. Pretendia, assim, convencer o legislativo da importância da ilha como uma reserva de recursos naturais para o país e confirmar sua vocação turística, principalmente no que dizia respeito à pesca.

A parte burocrática referente à questão fundiária para a criação do parque havia sido resolvida com a promulgação prévia da Lei Estadual no 2.370/1958, que autorizava o poder executivo estadual a realizar a doação da integralidade do território da ilha do Bananal para a União, sob a condição de ali se criar e implementar o Parque Nacional do Araguaia, no prazo de dois anos. Como a ilha do Bananal era declarada terra devoluta do estado de Goiás, a transmissão da propriedade se impunha como condição legal para a ingerência da União sobre o seu território. O fato dessa lei ser precedente ao PL, demonstra que existia uma articulação política bastante consolidada na esfera estadual no sentido de transformar a ilha do Bananal em área protegida.

o projeto estabelecia como obrigações, derivadas do ato constitutivo, a construção de um hotel de turismo, no interior do parque, e a manutenção de: a) postos de defesa e vigilância sanitária animal e vegetal, fiscalização de caça e pesca, e proteção aos índios; b) uma fazenda modelo; c) uma granja modelo; d) uma colônia de pescadores; e) lanchas para assistência técnica e sanitária aos criadores e agricultores fixados às margens do rio Araguaia, nos Estados do Mato Grosso, Pará, Maranhão e Goiás; f) serviço de revenda de arame farpado e grampos para cercas; g) serviço especial para a apreensão e preservação de todos os espécimes animais e vegetais da região, bem como os do território nacional adaptáveis à ilha do Bananal. ${ }^{29}$

Do ponto de vista estrito da conservação, o PL refletia a ideia de parque nacional como uma "vitrine natural" ou um tipo excepcional de "jardim

\footnotetext{
${ }^{28}$ Congresso Nacional, Câmara dos Deputados, Projeto nº 256/1959.

${ }^{29}$ Idem, art. 6.
} 
zoobotânico". A introdução de espécies exóticas serviria para "melhorar" a natureza da ilha do Bananal, enriquecendo a sua biodiversidade e tornando-a mais atrativa do ponto de vista turístico. Havia a convicção de que as condições naturais locais eram favoráveis à vida de todas as espécies da fauna e da flora brasileiras, sem que fosse necessário empregar grandes esforços para aclimatação.

Na realidade, as obrigações estabelecidas no artigo $6^{\circ}$ serviam mais aos interesses dos pecuaristas e agricultores instalados na região do que à proteção da natureza. No jargão parlamentar atual, o artigo poderia ser considerado um tipo especial de "jabuti" (emenda parlamentar que modifica um projeto de lei em discussão, de forma a alterar ou distorcer seu objetivo original), já que compunha a proposta original, mas não guardava nenhuma relação com a temática central da lei proposta. Ficava evidente a intenção de beneficiar a classe agropecuarista goiana. 0 deputado justificou a inclusão do dispositivo pela carência de assistência técnica agropecuária na região: "Pareceu-me, na redação do projeto, incluir a manutenção de alguns órgãos de assistência a setores da economia sertaneja, na realidade nada assistidos nas Regiões Norte e Centro-Oeste". ${ }^{30}$ As atividades previstas para "socorrer" os produtores rurais fugiam às atribuições da Seção de Parques e Florestas, responsável pela gestão dos parques nacionais dentro do Serviço Florestal do Ministério da Agricultura. Legalmente, elas se encontravam a cargo de outras instâncias dentro do mesmo ministério, o que gerava um conflito de atribuições administrativas. Costa reconhecia o problema, mas limitou-se a sugerir que o Parque Nacional do Araguaia deveria obedecer a uma "subordinação especial" a ser regulamentada futuramente.

Costa tinha pressa na aprovação da lei, pois caso não se cumprisse o prazo vinculado para o início das obras do parque, a União perderia o direito de propriedade sobre a ilha, inviabilizando a criação do parque. Para garantir que o projeto não se perdesse na morosidade burocrática das Comissões da Câmara, simultaneamente, Castro Costa levou, em maio de 1959, a proposta diretamente ao Presidente Juscelino Kubitschek. Tratava-se de "um expediente completo sôbre a ilha do Bananal, do qual constam o projeto 256, um mapa e a cópia da lei 2370 de Goiás [...]. Remetido tal expediente ao Ministério da Agricultura e ao DASP [Departamento Administrativo do Serviço Público] [...] dêle resultou decreto executivo de criação do Parque Nacional do Araguaia $[\ldots]^{\prime \prime}{ }^{31}$

\footnotetext{
${ }^{30}$ Câmara dos Deputados, justificativa do PL n.256/1959.

${ }^{31}$ Jornal Correio da Manhã, 20/06/1960, p.7.
} 
O Decreto do Executivo n 47.570 de 31 de dezembro de 1959, que criou o Parque Nacional do Araguaia, retomou, praticamente na íntegra, a proposta original do PL 256/1959, suprimindo apenas o problemático artigo 6º que impunha ao governo federal uma série de ações incompatíveis com a natureza dessas áreas e com o que havia sido estabelecido pelo Código Florestal de 1934:

Art. 9o - Os parques nacionaes, estaduaes ou municipaes constituem monumentos públicos naturaes, que perpetuam sua composição florística primitiva, trechos do paíz, que, por circunstâncias peculiares, o merecem.

$\S 1^{\circ}$ É rigorosamente proibido o exercício de qualquer espécie de atividade contra a flora e a fauna dos parques.

$\S 2^{\circ}$ Os caminhos de acesso aos parques obedecerão as disposições technicas, de fórma que tanto quanto possível, se não altere o aspecto natural da paisagem. ${ }^{32}$

Não se pode afirmar que as motivações de JK decorressem de um interesse genuíno nas áreas protegidas. Embora ele não fosse insensível à destruição das florestas brasileiras e reconhecesse a importância do uso racional dos recursos naturais e a necessidade de melhorar a eficiência da sua exploração, a conservação da natureza não constava entre as prioridades do seu governo.

A integração econômica da bacia do Araguaia não estava pontualmente incorporada às metas de planejamento de JK. Na visão de Lima Filho, ${ }^{33}$ ela surgiu durante a construção de Brasília, como um "capricho modernista de Juscelino Kubitschek". Teria nascido de uma "conversa de botequim", na qual o sertanista Acary de Passos de Oliveira teria sugerido ao presidente a construção de um hospital na ilha do Bananal. ${ }^{34}$ Segundo JK:

O meu ponto de vista em relação à ilha do Bananal era simples e objetivo. Tratava-se de um impulso a mais, na direção da Fronteira Ocidental. Para que esse alvo fosse atingido, seria necessário transformar a ilha em parque nacional. o parque seria a meta da marcha que eu iria iniciar, no sentido de estabelecer naquela região, até então deserta, núcleos agrícolas pioneiros para o pleno desenvolvimento das atividades agropecuárias. Como a ilha era um paraíso de caça e pesca, decidi construir no seu ponto mais favorável um hotel de turismo e, levando em conta as primitivas condições de vida na região, resolvi, simultaneamente, incorporar os índios que ali habitavam à civilização brasileira, criando para eles, serviços locais de assistência imediata [referia-se ao hospital indígena que pretendia construir na ilha]. ${ }^{35}$

\footnotetext{
${ }^{32}$ BRASIL, Decreto-Lei N. 23.793 de 23 de janeiro de 1934. Aprova o Código Florestal que com este baixa.

${ }^{33}$ LIMA FILHO, O desencanto... op. cit., p. 97

${ }^{34}$ OLIVEIRA apud LIMA FILHO, O desencanto... op. cit., p. 97.

${ }^{35}$ OLIVEIRA, 50 anos... op. cit., p. 382-383.
} 
No contexto da política de integração nacional de JK, o parque nacional do Araguaia respondia aos objetivos da expansão do capital na fronteira Oeste, tendo como ponto de partida o desenvolvimento do "turismo selvagem" na ilha do Bananal. Para tanto, era preciso equipar a ilha com uma infraestrutura mínima de serviços turísticos. O primeiro passo seria construir um "aeroporto”, já que o isolamento da região não permitia um fácil acesso por terra. 0 segundo, seria oferecer um meio de hospedagem confortável, que garantisse comodidades e pequenos luxos aos visitantes. Por fim, era necessário melhorar as condições sanitárias locais e propiciar saúde e educação para as populações indígenas e sertanejas. Estava montada a Operação Bananal.

Há nove meses do fim do mandato presidencial, a criação do PNA representava uma valiosa oportunidade para JK vincular o seu governo a mais uma realização, um último ato épico para incorporar o interior à nova engrenagem econômica do país. Se bem-sucedido, Juscelino veria seu capital político aumentar consideravelmente. Por outro lado, a consolidação da nova capital federal era um imperativo. Neste sentido, ao conceber o PNA como vetor de desenvolvimento da grande zona interiorana do Brasil Central, JK fortalecia o papel de Brasília como epicentro nacional, de onde e para onde afluiria o progresso do país.

Apesar disso, a criação do PNA não se insere unicamente na narrativa da Marcha para o Oeste, reinterpretada e atualizada por JK. Ela se situa em um contexto social e político mais abrangente, que incluiu, entre outras questões, as preocupações com a conservação da natureza. O Araguaia não foi o único parque nacional instituído no período JK (1956-1961). O ato normativo de sua criação fez parte de um pacote de decretos presidenciais que, nos dois últimos anos de seu mandato, constituiu cinco parques nacionais: Ubajara (1959), no Estado do Ceará, Aparados da Serra (1959), no Rio Grande do Sul, Araguaia (1959), no atual estado do Tocantins, Tocantins (1961) - hoje Chapada dos Veadeiros - e Emas (1961), ambos no Estado de Goiás.

Para entender a inserção, mesmo que modesta, da pauta ambiental no período JK, é importante considerar o contexto dos debates sobre a proteção da natureza, que vinham sendo travados no Brasil há tempos, por cientistas ligados às instituições de pesquisa nacionais, em especial ao Museu Nacional do Rio de Janeiro, técnicos, funcionários públicos e sociedade civil. 


\section{A conservação da natureza na era JK}

Segundo Urban, ${ }^{36}$ o apelo desenvolvimentista de JK gerou grande apreensão entre técnicos do próprio governo, cientistas e profissionais liberais defensores da conservação da natureza no Brasil. Esta era a primeira vez que um governo impunha transformações tão drásticas, em um espaço temporal tão curto. A perspectiva de um crescimento econômico sem os devidos cuidados com a natureza despertou o receio de que os efeitos, a médio e longo prazo, fossem devastadores e irreversíveis. Do ponto de vista da conservação, a ostensiva política de integração nacional soava como uma sentença condenatória às regiões ainda pouco impactadas pela ocupação humana. O problema não era o desenvolvimento em si, reconhecido como necessário ao país, mas a sua concepção, que elegia os aspectos econômicos como a única variável válida e otimizava seus benefícios a curto prazo, sem levar em consideração o custo da destruição da natureza e suas consequências futuras.

A organização da Fundação Brasileira para a Conservação da Natureza (FBCN) veio como respostas a esse contexto. Ela foi a primeira sociedade civil de alcance nacional voltada para uma ação mais abrangente de conservação da natureza. ${ }^{37} \mathrm{~A} F \mathrm{BCN}$ nasceu com a missão de atuar de modo pragmático junto ao poder público e à sociedade para formar uma mentalidade conservacionista no Brasil.

O grupo inicial da $\mathrm{FBCN}$ era formado por profissionais que desempenhavam funções públicas junto a órgãos públicos como o Departamento de Produção Vegetal do Ministério da Agricultura, o Conselho Florestal Federal, o Serviço Florestal do Distrito Federal, como era o caso dos engenheiros agrônomos Wanderbilt Duarte de Barros, Arthur Miranda de Bastos, Harold Edgar Strang e Victor Abdennur Farah; e por profissionais liberais de várias áreas: Fuad Atala e Rossini Pinto, jornalistas, Luiz Hermany Filho e Francisco Iglesias de Lima, industriais, Eurico Santos e Luiz Simões Lopes, escritores, Rosalvo de Magalhães, excursionista, Fernando Segadas Vianna, biólogo, Heitor Grilo, agrônomo e professor, e a emblemática figura de Jerônimo Coimbra Bueno, então Senador da República. ${ }^{38}$

\footnotetext{
${ }^{36}$ URBAN, Tereza. Saudade do Matão. Relembrando a história da conservação da natureza no Brasil. Curitiba: UFPR, 1998.

${ }^{37}$ Sobre essa questão ver: DEAN, A ferro... op. cit.; FRANCO, José Luiz Andrade.; DRUMMOND, José Augusto. Nature Protection: the FBCN and Conservation Initiatives in Brazil, 1958-1992. In: HALAC, vol. II, n.2, mar/ ago. 2013, p. 338-367.
}

${ }^{38}$ FRANCO; DRUMMOND; Nature... op. cit. 
Essa articulação entre agentes públicos e sociedade civil, tendo como princípio funcionar como elemento de pressão social sobre os governos, não era uma novidade no Brasil. Ela foi notada por Franco e Drummond em seu estudo sobre a geração precedente de protetores da natureza, 1920-1940. ${ }^{39}$ $\mathrm{O}$ engajamento de um público leigo acabou dando maior visibilidade à $\mathrm{FBCN}$ e à questão da conservação da natureza. A maior parte dessas pessoas eram oriundas de uma classe média bem instruída, com hobbies - montanhismo, excursionismo, escotismo, exploração de cavernas, observação de pássaros, cultivo de orquídeas - que as tornavam mais conscientes da relação entre o desenvolvimento econômico e a destruição da natureza. ${ }^{40}$

Nos primeiros anos de funcionamento, a FBCN atuou de maneira mais restrita, sobretudo quando comparada com a sua expansão e com o papel que veio a desempenhar no cenário nacional nas décadas seguintes. Sem recursos suficientes para a implementação de ações diretas, a FBCN buscou alcançar seus objetivos por intermédio de indivíduos capazes de influenciar pessoalmente as decisões nas altas esferas da política nacional. A indicação de Jerônimo Coimbra Bueno, então Senador da República pelo estado de Goiás, para o cargo de presidente em 1960, é emblemática desta opção. Sua presença no Senado, naquele momento, representava uma oportunidade privilegiada de dar maior visibilidade a entidade e conquistar o apoio do Legislativo à pauta conservacionista. Entre 1958 e 1963, quando se encerrou o seu mandato como senador, Coimbra Bueno foi a voz da FBCN no Congresso Nacional. ${ }^{41}$

\section{A articulação política de Coimbra Bueno em defesa do Parque Nacional do Araguaia}

Coimbra Bueno, como vimos, possuía experiência política e uma trajetória de atuação pública na defesa da conservação da natureza em Goiás. No Senado, ele destacou a relevância e seriedade dos propósitos da FBCN. Ele propôs o Projeto de Lei no $23 / 1960$, que declarava a utilidade pública da FBCN. Mas, o seu principal embate no Congresso Nacional foi pela criação de áreas naturais protegidas. Na tribuna do Senado, Coimbra Bueno defendeu a necessidade de o Brasil ampliar o número dessas áreas, pois, considerando a dimensão e a diversidade do território nacional, as reservas existentes eram insuficientes para garantir a conservação da fauna e da flora: "Acredito que

\footnotetext{
${ }^{39}$ FRANCO; DRUMMOND, Proteção à Natureza... op. cit.

${ }^{40}$ DEAN, A ferro... op. cit.

${ }^{41}$ FRANCO; DRUMMOND, Nature ..., op. cit.
} 
em decorrência da transferência da Capital para o Planalto Central, nossos imensos recursos naturais estão correndo risco de mutilações irremediáveis, tal como aconteceu com o litoral, quase todo erodido e com várias espécies da fauna e flora ameaçados de extinção total". ${ }^{42}$

A questão do momento e da oportunidade para que as áreas protegidas fossem criadas, com a mudança da capital para Brasília e com a construção de estradas para a integração nacional, foi um aspecto sobre o qual Coimbra Bueno argumentou insistentemente:

Sr. Presidente [do Senado], sou dos que aplaudem e tecem encômios aos ideais do Sr. Presidente da República de criar imediatamente, o / parque Nacional da Ilha do Bananal. Além do mais, entendo que S. Exa. deve aproveitar o momento da mudança da Capital, como a última oportunidade oferecida ao País para a criação de grandes reservas nacionais, principalmente nos Estados centrais, antes que a ocupação geral do território, primeira consequência natural de Brasília, se verifique, elevando os preços dos terrenos a níveis incompatíveis com a criação de tais reservas.

A hora de agir é a presente - não amanhã - ainda no atual período governamental, porquanto a função precípua de Brasília, a principal razão da interiorização da Capital é a integração territorial e consequentemente, a valorização das terras até então abandonadas. As estradas Brasília - Belém, verdadeira espinha dorsal do território cortando o País de Norte a Sul; Brasília - Acre; Brasília-Campinho; Brasília - Vitória; Brasília - Santos e a BR 14, que demandará o extremo Sul do nosso País, tôdas (sic) as rodovias em execução acelerada, estão provocando enorme elevação dos preços das terras. (...) ainda há poucos dias, assisti, em Jataí [Goiás], homens adquirindo terras a preço quatro ou cinco vêzes (sic) superior ao que vigorava há apenas cinco ou seis meses. A valorização está se estendendo rapidamente a todo o Estado do Mato Grosso, provavelmente, a esta altura, também ao Pará e, dentro em pouco, ao Amazonas e talvez ao próprio Acre e demais Territórios. Portanto, a ideia é feliz e talvez seja a última oportunidade para se cogitar prontamente, e ainda no corrente exercício, da criação de grandes reservas naturais à preservação da flora e da fauna nas diversas regiões do País. ${ }^{43}$

A ausência, na grande maioria dos estados brasileiros, de uma política fundiária capaz de estabelecer um controle razoável do processo de ocupação do território e dos preços das terras públicas favorecia a ação de grupos especuladores que atuavam na grilagem de terras, muitas vezes com a conivência de políticos locais, notários e até mesmo de governadores. A irregularidade

\footnotetext{
${ }^{42}$ Ver: Diário do Congresso Nacional N. 57, maio de 1960, p.1096; Diário do Congresso Nacional, 09 de abril de 1960, p. 936.

${ }^{43}$ Diário do Congresso Nacional, 28 de maio de 1960, p. 1223; Diário do Congresso Nacional, 04 de junho de 1960, p. 1274, respectivamente.
} 
na compra e venda das terras devolutas, assim como a migração espontânea, produzia consequências sociais, mas também ambientais, na medida em que aumentava a pressão sobre novas glebas, resultando em intensa depredação da fauna e da flora. Portanto, era consenso entre os conservacionistas a urgência em agir para garantir o máximo possível de áreas naturais para a conservação.

O esforço para a criação de reservas e parques nacionais parece ter sido a principal diretiva da FBCN na sua fase inicial. Apesar da atuação de Coimbra Bueno no Congresso Nacional, o avanço na constituição de novos parques não veio do Legislativo, mas da sua articulação política direta junto ao chefe do Executivo federal. Coimbra Bueno foi o braço forte de JK no Senado Federal no que dizia respeito à Brasília. Desde a década de 1940, impactado pela renovação modernista com a construção de Goiânia, ele passou a advogar em favor da causa mudancista. Criou a Fundação Coimbra Bueno pela Nova Capital exclusivamente para este fim. Também participou voluntariamente das diversas Comissões do Governo Federal pró-interiorização da capital, entre 1946 e 1961. Durante a campanha presidencial que elegeu JK, foi o principal responsável pela disseminação e fortalecimento da ideia da mudança, chegando a interpelar todos os candidatos a esse respeito. $\mathrm{O}$ apoio declarado a JK só veio após o compromisso de que faria Brasília. Apesar de pertencer à UDN, partido de oposição ao presidente, filiado ao PSD, Coimbra Bueno costurou com a bancada udenista no Senado o acordo que garantiu a aprovação de todos os atos do governo que envolviam Brasília:

Mas nós tínhamos lá uma bancada de 16 udenistas no Senado. Essa bancada ia decidir os destinos de Brasília. (...) evoluiu da seguinte forma: eu teria o apoio total da UDN em todos os assuntos de Brasília, apoiando Juscelino ou quem quiser, contanto que não saísse da linha de Brasília. O partido era de oposição, mantinha-se na oposição, mas no caso de Brasília, eu votava por 16, sempre votei pelo Senado, pela nossa bancada, me deram confiança plena. (...) o Juscelino só conseguiu apoio no Congresso, com a votação maciça do Senado. ${ }^{44}$

O suporte estratégico de Coimbra Bueno reforçou a relação de confiança e proximidade com o presidente: "Eu ia no Palácio, tinha aquela fila de senadores e deputados do PSD eu ia entrando diretamente pra mim (sic) falar com o presidente, isso é que é uma coisa... Eles ficavam indignados comigo e o pessoal da UDN também tinha lá seu fundo de tacho". ${ }^{45}$

\footnotetext{
${ }^{44}$ BUENO, Jerônimo Coimbra, Depoimento de Jeronimo Coimbra Bueno - Programa de História Oral, Arquivo Público do Distrito Federal, Brasília, 1990.

${ }^{45}$ Idem, p.9.
} 
Coimbra Bueno esclarecia que o respeito e a confiança de JK haviam sido conquistados há muitos anos, em um episódio quando este era prefeito de Belo Horizonte. Naquela época, Bueno foi convidado por JK para fazer o plano de reurbanização da capital mineira, mas o desaconselhou a levar a ideia adiante, sob pena de uma derrocada política. JK acabou decidindo realizar apenas intervenções urbanas pontuais, como foi o caso do complexo da Pampulha. Isto garantiu o sucesso de seu mandato, alavancando sua carreira política. Segundo Coimbra Bueno: "Mais tarde, ele [JK] ficou gratíssimo a nós [Bueno e o urbanista Alfred Agache] e sobretudo a mim, que eu sempre travei com ele um relacionamento pessoal muito bom. Ele então, tinha completa confiança, sobretudo em mim, confiança pessoal. Isso foi muito útil, para a realização de Brasília". ${ }^{46}$

A narrativa de Coimbra Bueno sobre como se deu a assinatura dos decretos de criação dos parques nacionais da Chapada dos Veadeiros, na época nomeado de "Tocantins", e das Emas, é elucidativa de como foi possível expandir as áreas protegidas naquele período. Demonstra também, o importante papel desempenhado por Coimbra Bueno no movimento conservacionista brasileiro.

(...) o Juscelino certas vezes me deixou até... assim, meio chocado. Eu dava um papel pro Juscelino, por exemplo, um belo dia ele me autorizou a criar dois parques nacionais, que eu sempre tive paixão por esse negócio de parques, essa coisa, Parque Nacional das Emas e Parque Nacional do Tocantins. Eu podia falar: "Você me apóia nisso, Juscelino, porque eu vou fazer assim mesmo e tudo o mais. E quero sua palavra." Ele disse: "Você pode fazer." Me deu um trabalho enorme, engrossei dois livros assim, dois volumes enormes, ficou tudo prontinho só dependendo da assinatura final dele. Ele disse o seguinte: "Olha, eu tô muito atropelado, eu vou fazer uma viagem de avião aí pros Estados Unidos, sei lá o quê, fazer, umas visitas, você vai comigo e no avião...” - Isso ele fez várias vezes comigo - "... e no avião, eu vou ter tempo, você me submete a esse assunto." "Tá bem.” Assim ele levou o catatau. Ele chegou no avião, lhe deu um prego tremendo e ele foi dormir. Dormiu o tempo todo, cada lugar que ele chegava ele voltava mais pregado. Quando chegou no final eu já tava furioso, andei três dias e ele nada de me dar tempo pra ir lá assinar e considerar o negócio. Ele tava com um catatau no braço assim na saída, na hora que nós íamos deixar o avião, ele falou: "Não, olha aí, ô Coimbra, onde é que assina, aí" “Tu não leu nada, nem, só leu o título." "Onde é que assina?” Assinou mesmo. Quer dizer, essa coisa, eu gozei, essa confiança eu tinha, isso também anima a gente a trabalhar por alguém. Porque o Juscelino era de um partido contra mim, tinha plena confiança. ${ }^{47}$

\footnotetext{
${ }^{46}$ Idem, p.6.

${ }^{47}$ Idem, p.17-18.
} 
Embora a FBCN não tenha desenvolvido uma atuação muito ampla em seus anos iniciais, o encaminhamento desses dois parques demonstra como, por meio da influência política de Coimbra Bueno, foi possível algum avanço, mesmo quando o discurso desenvolvimentista era hegemônico. A mesma lógica se repetiu com a criação de mais seis parques nacionais - Caparaó, entre minas Gerais e Espírito Santo, Sete Cidades, no Piauí, São Joaquim, em Santa Catarina, Tijuca, no Rio de Janeiro, Brasília, no Distrito Federal e Monte Pascoal, na Bahia - pelo sucessor de JK, Jânio Quadros. Dessa vez, foi Victor Abdennur Farah, diretor executivo da FBCN, que foi presidente do Conselho Florestal Federal e amigo pessoal do presidente, a influência decisiva. ${ }^{48}$

\section{O Parque Nacional do Araguaia no contexto da Operação Bananal}

A Operação Bananal foi deflagrada em maio de 1960, com prazo estabelecido para conclusão no final de dezembro do mesmo ano. JK convocou Oscar Niemeyer para fazer os projetos arquitetônicos dos edifícios que comporiam o núcleo turístico do PNA: um elegante Hotel de Turismo, uma casa independente que serviria de residência oficial de férias do presidente, um pequeno hospital e uma escola de ensino básico. A coordenação das obras foi designada à Fundação Brasil Central (FBC), criada por Getúlio Vargas durante o período do Estado Novo (1937-1945), com a função de coordenar o desbravamento e promover a colonização das imensas áreas do Brasil Central, e extinta, em 1967, com suas funções delegadas para a Superintendência de Desenvolvimento do Centro-Oeste (SUDECO). A FBC também ficou encarregada de construir o aeroporto, que consistia em uma pista de pouso com uma pequena estação de embarque, e a infraestrutura de suporte à operação - dez casas destinadas a abrigar os trabalhadores e o armazenamento de mantimentos, materiais e equipamentos. Esse conjunto de construções correspondia à primeira etapa da Operação Bananal. Ainda estava prevista a construção de outras casas, semelhantes à residência presidencial, os Ranchos JK, em outros pontos da ilha. Estes ranchos seriam levantados de forma gradual e serviriam como apoio e incremento do turismo no parque. ${ }^{49}$

Para assegurar o controle da operação, JK nomeou para a presidência da FBC o Coronel Nélio Cerqueira Gonçalves e para seus auxiliares o engenheiro Juca Chaves e o sertanista Acary de Passos Oliveira, grande conhecedor dos sertões do Araguaia. Para viabilizar as obras, JK ordenou a realocação

\footnotetext{
${ }^{48}$ FRANCO; DRUMMOND, Nature... op. cit.

${ }^{49}$ Fundação Brasil Central, Ofício, 1961.
} 
de recursos da Superintendência do Plano de Valorização Econômica da Amazônia (SPVEA) para a Operação Bananal. A transação foi formalizada mediante um convênio entre a SPVEA e a FBC.

A investida colonizadora de JK sobre a ilha do Bananal causou alarde imediato. Alguns jornais publicaram matérias sensacionalistas superdimensionando a operação. Falava-se da construção de uma segunda Brasília e de um hotel com 500 apartamentos. Adversários políticos de JK referiam-se à Operação Bananal como "plano paranoico", "delírio", "aventura imposta pela nervosa filosofia de ação", "Bananacap". Acusavam o presidente de arquitetar um plano para minar o governo sucessor, já que este herdaria uma "bananosa". ${ }^{50}$

A edição do jornal Correio da Manhã de primeiro de junho denunciou a "Corrida de grileiros sôbre o Bananal provocada pelo turismo do gôverno". Segundo a matéria, desde o anúncio da "meta Bananal", uma horda de aventureiros estava invadindo as terras "sem dono" nos estados de Mato Grosso e Goiás. Os possuidores de concessões de terras públicas, que até aquele momento nada haviam feito, passaram a investir na colonização e a demanda por novas concessões cresceu. $\mathrm{O}$ aquecimento do mercado de terras aumentou a incidência de títulos duvidosos e os conflitos fundiários. Os moradores locais se apressaram em transformar seus ranchos em hospedarias, para fazer concorrência com o hotel do governo.

A corrida pela terra, fosse de forma legal ou ilegal, acentuou o problema da destruição da fauna e da flora. Nos moldes propostos por JK, o parque nacional do Araguaia era qualificado mais como um balneário turístico do que como uma área de conservação. Para os conservacionistas da $\mathrm{FBCN}$, a ideia de parque nacional implicava a preservação integral do ambiente natural, o que significava a ausência da caça e da pesca, em qualquer de suas modalidades, e de moradores, permanentes ou temporários, no seu interior. Se até a década de 1950, a destruição ambiental na ilha do Bananal representava o preço do atraso, a partir da Operação Bananal, ela passava a representar o preço do progresso.

A construção do hotel e dos ranchos no interior do PNA seguia um padrão comum aos parques nacionais norte-americanos. Nos EUA, era usual parques possuírem estruturas para acomodação dos visitantes, como hotéis, áreas de camping e estacionamento para trailers, além de restaurantes e lanchonetes, lojas de souvenirs, estradas interiores etc. Outros parques nacionais

${ }^{50}$ Ver: Jornal Correio da Manhã, 10/05/1960, p. 6; Jornal do Brasil, 11/05/1960 e 13/05/1960. 
brasileiros seguiam este modelo. O Parque Nacional do Itatiaia, quando criado, incorporou parte de uma estrutura hoteleira existente na região. No Parque Nacional do Iguaçu, foi projetado um grande hotel de turismo, que foi inaugurado somente em 1956, no primeiro ano do governo de JK. ${ }^{51}$

Então, a ideia de criar um parque nacional na maior ilha fluvial do mundo e ali construir um hotel de turismo parecia lógica. Até porque a região não oferecia condições para fazer o receptivo de turistas mais abastados como desejava JK. O que diferenciava o turismo proposto no PNA era o fato de se permitir a caça e a pesca no seu interior. Nos EUA, a visitação estava voltada para a contemplação e o lazer em contato com a natureza. Tratava-se de um tipo de turismo sensitivo, que tinha por finalidade despertar o amor e a valorização da natureza e, como consequência, a vontade de preservá-la.

Embora Coimbra Bueno defendesse o PNA, ele se opôs incisivamente ao projeto de JK. Na sua perspectiva, a função do parque era garantir a conservação da flora e da fauna, o que somente seria alcançado com a proteção integral do seu território. Isto exigia não somente a realocação do centro turístico, mas também a retirada de todos os residentes humanos da ilha, ou seja: índios, posseiros e criadores de gado.

Coimbra Bueno sustentava que nem mesmo os índios podiam permanecer no parque. Nas suas palavras: "o índio liquida até o último animal e de seus filhos até o beija-flor não escapa". Ele propunha a sua transferência para as outras aldeias ao longo do Araguaia, onde deveriam ser assistidos pelo Estado. Os demais moradores da ilha também teriam de ser retirados. Quanto ao centro de turismo, entendia que o ideal era que fosse instalado no continente, em algum ponto da margem mato-grossense do Araguaia. No entorno do PNA, sugeriu a delimitação de uma área controlada, para o desenvolvimento do turismo e da colonização: “A ideia não é fazer propriamente da ilha do Bananal um centro de turismo, mas apenas uma grande reserva nacional de preservação da flora e da fauna, que poderá servir também de atrativo secundário de turismo, se circundarmos a ilha com grandes extensões de terras controladas para a caça e a pesca nacionalizadas e portanto, perenes". ${ }^{2}$

A proposta defendida por Coimbra Bueno não permitia nenhuma atividade humana no interior do PNA e constituía no seu entorno uma zona controlada de aproximadamente $200.000 \mathrm{~km}^{2}$, onde seria permitido a caça e a pesca monitoradas, a construção de pequenos meios de hospedagem, do centro turístico, aeroporto e até uma pequena cidade planejada. Essa zona

\footnotetext{
${ }^{51}$ Ver: Jornal Correio da Manhã, 01/11/1956, p.1.

${ }^{52}$ Diário do Congresso Nacional, 04 de junho de 1960, p. 1275.
} 
poderia ser ampliada, aproveitando-se terras devolutas dos estados de Mato Grosso, Goiás e Pará, para a colonização e a pecuária assistidas pelo governo. Este exerceria o controle e a fiscalização tanto no interior do PNA como na zona controlada, por meio de guardas-florestais.

Para Coimbra Bueno, a implantação da zona controlada significava uma "inovação incomum" ${ }^{53}$ De fato, a sugestão era arrojada para a época. A gestão dos parques nacionais brasileiros não contemplava o controle das áreas limítrofes, e também ainda não existia nenhuma previsão legal para isso. A zona controlada antecipava a ideia atual de zona de amortecimento ou zona tampão, estabelecidas legalmente muitos anos depois. De toda forma, nenhum desses argumentos ou sugestões logrou sucesso. JK estava decidido a fazer da ilha um balneário turístico para os habitantes da nova capital, Brasília.

Do ponto de vista administrativo, a Operação Bananal acabou produzindo uma situação sui generis, pois retirou das mãos da Seção de Parques Nacionais do Serviço Florestal a autonomia para implementar e gerir o PNA. O relatório anual do Ministério da Agricultura de 1960 apontava que:

\begin{abstract}
Graças a especial atenção do Sr. Presidente da República vários recursos, que não do S. F. [Serviço Florestal], foram empregados na Ilha do Bananal, por intermédio da Fundação Brasil Central. Com esses (sic) recursos, foram construídos o aeroporto, o hotel de turismo e a residência oficial do Senhor Presidente. O S. F. destacará para 1961 uma verba destinada aos primeiros serviços da preservação da flora e fauna e das belezas naturais da ilha, pela criação de uma polícia florestal.

Os trabalhos da instalação do Parque prosseguem com grande entusiasmo em virtude do emprego daqueles mencionados recursos. ${ }^{54}$
\end{abstract}

Nos anos que se seguiram à Operação Bananal, nem mesmo um posto da polícia florestal foi instalado na ilha. Dentre as atribuições da FBC não constavam a criação e a gestão de áreas protegidas, portanto seus técnicos e funcionários não tinham orientação técnica ou qualquer proximidade com os princípios da conservação. Na realidade, a FBC funcionava dentro da lógica de expansão da fronteira. Este aspecto fica evidente no relatório das atividades do ano de 1960, no contexto da Operação Bananal. O documento enfatizava o entusiasmo e o espírito pioneiro dos quais se revestiram os trabalhos na ilha do Bananal. E destacava positivamente a disposição dos caboclos existentes na ilha, em razão das benfeitorias que estavam sendo realizadas. Também considerava positivo o processo migratório desencadeado pela operação: "Pelo

\footnotetext{
${ }^{53}$ Idem.

${ }^{54}$ Ministério da Agricultura, Relatório, 1960, p. 85.
} 
Rio Araguaia, chegam embarcações típicas do nosso interior e seus tripulantes já sabem que ali encontrarão o apôio (sic) da Fundação Brasil Central". ${ }^{55}$

Diferentemente dos demais parques nacionais, o PNA era entendido pelas pessoas que estavam à frente da sua implementação como um projeto de colonização. 0 mais provável é que nenhuma delas possuísse familiaridade com parques nacionais ou qualquer outra categoria de área protegida. A perspectiva que prevaleceu sobre a finalidade do PNA foi contraditória àquela defendida por Coimbra Bueno e por seus companheiros conservacionistas da FBCN.

\section{Considerações finais}

Durante a primeira metade do século XX ocorreram mudanças estruturais significativas na região do médio Araguaia, como consequência de políticas públicas de integração do espaço interior à economia nacional. Consideramos neste trabalho dois momentos específicos da expansão da fronteira Oeste: i) a campanha da Marcha, durante o Estado Novo; e ii) a construção de Brasília, sob o plano de integração nacional do governo JK. Eles marcam uma ocupação mais densa do vale do Araguaia, decorrente de ondas migratórias. Como resultado dessas políticas consolidaram-se a frente pecuária, o extrativismo animal e um tipo de turismo de caça e pesca, que teve a ilha do Bananal como principal atrativo, tornando-a o palco das disputas características de uma típica fronteira de exploração. Nesse sentido, o PNA pode ser entendido como um elemento da fronteira, fruto do projeto nacional-desenvolvimentista.

Essas mudanças, sustentadas pela ideologia do progresso, foram responsáveis pela intensificação da caça e da pesca profissional e pelo estabelecimento de um turismo de características altamente predatórias na ilha. Isto favoreceu a emergência, por parte de atores locais, de preocupações relacionadas com a destruição da natureza e com a sua valorização como patrimônio natural. Esses atores criticaram a falta de uma atuação incisiva dos governos estadual e federal no sentido de coibir o abusivo extrativismo animal na região e cobraram do poder público a transformação da ilha do Bananal em uma zona de proteção da fauna e da flora silvestres. Na sua concepção, a transformação da ilha em um parque nacional visava garantir que restasse alguma vida selvagem para ser apreciada pelas gerações vindouras. Neste trabalho, destacamos: (i) a sensibilidade de Leolídio di Ramos Caiado para a preservação das paisagens naturais e da fauna do Araguaia; (ii) a atuação

${ }^{55}$ Fundação Brasil Central, Relatório de Atividades, 17/01/1960, p. 4. 
política de Gerson de Castro Costa e, principalmente, de Jerônimo Coimbra Bueno em defesa da criação do parque nacional do Araguaia. O posicionamento contrário à destruição da vida selvagem do Bananal presente no discurso desses personagens e seu esforço no sentido de protegê-la, por intermédio da criação de um parque nacional, demonstram que em Goiás já existia um discurso e uma preocupação sintonizados com o movimento conservacionista brasileiro da primeira metade do século XX.

A incorporação da bacia do Araguaia ao projeto de interiorização do desenvolvimento, cujo núcleo foi a construção de Brasília, se deu através da implementação do PNA, reunindo um conjunto de ações consolidadas na 'Operação Bananal'. Tal operação, a cargo da agência colonizadora FBC, impôs ao parque uma administração atípica, quando a retirou da Seção de Parques Nacionais do Serviço Florestal do Ministério da Agricultura, agência responsável pela gestão das áreas protegidas na esfera federal. A ingerência da FBC fez com que os técnicos que atuavam na conservação não tivessem nenhuma autoridade sobre o PNA nos seus primeiros anos. Esta condição foi prejudicial à conservação, pois a visão dos técnicos da FBC sobre o PNA era a de um projeto de colonização e não a de uma área de conservação.

Além da FBC, o PNA esteve, desde sua criação, sujeito a políticas indigenistas, por meio da atuação do SPI. Como no período prevaleceu o intuito de incorporar os índios à sociedade nacional, por meio de sua transformação em trabalhadores rurais, o PNA acabou sendo submetido aos padrões regionais de ocupação territorial e uso dos recursos naturais, envolvendo a formação de fazendas de criação de gado no seu interior, o arrendamento de extensas áreas de pastagens, a invasão de suas terras por pequenos posseiros e grandes fazendeiros da região. A forma como o turismo de caça e pesca no interior da ilha foi estimulado pelos agentes do SPI desconsiderava os objetivos da conservação e a própria finalidade do PNA. Na época da sua criação, a visão que prevaleceu foi muito diferente da que era defendida pelos conservacionistas e especialmente por Coimbra Bueno, que não admitia a presença humana no interior da ilha do Bananal e tampouco a exploração dos seus recursos naturais, o que teve e tem, até hoje, consequências sérias para a gestão do parque.

Artigo recebido para publicação em 03/08/2020

Artigo aprovado para publicação em 14/11/2020 